\title{
Experimental study on the basic physical properties of diesel contaminated soil
}

\author{
Xiaohong $\mathrm{He}^{1, *}$, Fan $\mathrm{Liu}^{2}$, Guang $\mathrm{Li}^{3}$, Hai $\mathrm{Lu}^{3}$ \\ ${ }^{1}$ Changchun Sci-Tech University, College of Civil Engineering and Architecture, 130600 Changchun City, Jilin Province, China \\ ${ }^{2}$ Jilin Province Communication Planning and Design Institute, 130600 Changchun City, Jilin Province, China \\ ${ }^{3}$ Key Laboratory of Songliao Aquatic Environment, Ministry of Education, Jilin Jianzhu University, Changchun City, Jilin Province, \\ China
}

\begin{abstract}
In order to study the change of the properties of petroleum contaminated soil, the samples of diesel contaminated soil with different degrees of pollution were prepared manually, and their basic physical properties were tested through the particle test, specific gravity test and liquid plastic limit test. The results show that the diesel oil has a great influence on the particle size composition of soil, and the diesel oil makes the content of silt decrease, while the clay increase obviously; the specific gravity of soil sample decreases with the increase of oil content, and it is smaller than the proportion of unpolluted soil sample; the influence of diesel oil on the liquid-plastic limit of soil is different, the plastic limit of soil decreases with the increase of oil content, and the liquid limit increases first at a certain oil content, it reaches a peak value and then decreases.
\end{abstract}

\section{Background}

Petroleum is a wide range of energy and chemical materials. With the growth of energy demand, a large number of crude oil and its products enter into water, air and soil. In recent years, land pollution caused by oil spill is common. Because of the high difficulty and high cost of dealing with the contaminated sites, the oil spill has become a serious environmental problem. There are many reasons for oil leakage, such as damaged pipelines, oil tank accidents, coastal facilities discharge, onshore oil product leakage ${ }^{[1]}$. The figure below shows a large amount of diesel leakage caused by the pipeline cut during the construction of water company in Sinopec Jinan Qingdao section in 2012.

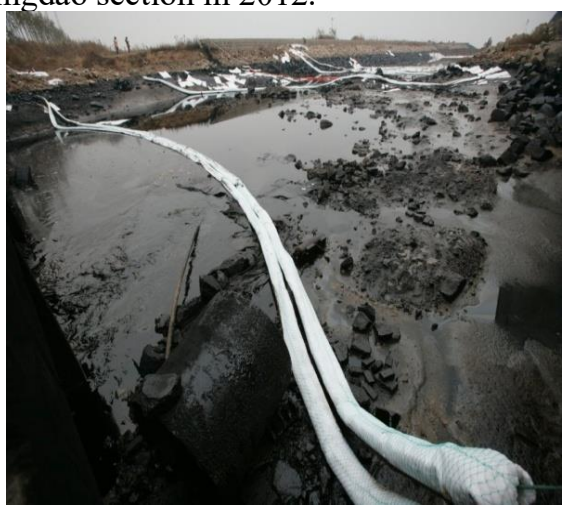

Fig. 1. Pictures of diesel oil leakage accident

Hydrocarbon pollutants not only affect the quality of soil, but also change the physical and mechanical properties of oil contaminated soil. This will lead to geotechnical problems in buildings or infrastructure built on contaminated soil ${ }^{[2]}$. In China, the research on polluted soil is relatively backward, most of which are about environmental protection and soil science, and the achievements in pure geotechnical engineering are few [3]. Petroleum contaminated soil can be used in many projects, such as subgrade, backfill, landfill liner, foundation materials and parking lot. So it is very important to understand the various properties of the contaminated soil, which will not only reduce the engineering cost due to the reuse of the contaminated soil, but also ensure the safety of the environment.

In order to further study the influence of oil on the basic physical properties of soil samples, diesel oil is selected as the representative oil, and the basic physical properties of diesel contaminated soil are tested through indoor geotechnical tests, mainly including particle test, specific gravity test and liquid plastic limit test. The study on the change of the basic properties of diesel contaminated soil is of practical significance to guide the treatment of contaminated soil and the application of engineering construction.

\section{Artificial preparation of diesel contaminated soil}

\subsection{Soil samples}

The soil samples used in the experiment were taken from Changchun Cultural Square, Jilin Province. The sampling depth is within $1 \mathrm{~m}$ of the surface, and the soil

\footnotetext{
*Corresponding author: hexh0605@126.com
} 
sample has not experienced oil pollution under natural conditions. The soil sample shall be dried by natural air, cleaned, crushed, screened by $0.5 \mathrm{~mm}$ and stored for future use ${ }^{[1]}$. The results show that the air drying water content of soil sample is $4.9 \%$, liquid limit is $39.9 \%$, plastic limit is $21.9 \%$, and plastic index is 18.0 .

\subsection{Petroleum products}

The oil used in this test is - 10 \# light diesel, and its basic physical properties are shown in Table 1.

Table 1. Basic physical properties of diesel oil

\begin{tabular}{|c|c|c|c|}
\hline Name & $\begin{array}{c}\text { Density } \\
/\left(\mathrm{g} \cdot \mathrm{cm}^{-3}\right)\end{array}$ & $\begin{array}{c}\text { Kinematic } \\
\text { viscosity }\left(20^{\circ} \mathrm{C}\right) / \\
\left(\mathrm{mm}^{2} / \mathrm{s}\right)\end{array}$ & $\begin{array}{c}\text { Freezing } \\
\text { point } /\left({ }^{\circ} \mathrm{C}\right)\end{array}$ \\
\hline $\begin{array}{c}-10 \# \text { diesel } \\
\text { oil }\end{array}$ & 0.840 & $3.0 \sim 8.0$ & -10 \\
\hline
\end{tabular}

\subsection{Preparation of artificial polluted soil sample}

During the preparation of soil samples, due to the good fluidity of diesel oil, the soil samples can be directly mixed with diesel oil to form artificially polluted soil samples ${ }^{[4]}$. In order to study the influence of diesel oil on the basic physical properties of soil samples under different pollution levels, the polluted soil samples with oil content of $0 \%, 4 \%, 8 \%, 12 \%$ and $16 \%$ were prepared respectively(the oil content is calculated according to the ratio of oil quality to dry soil quality). In the process of sample preparation, a certain quality of natural air dried soil sample is taken, and then the amount of diesel oil calculated quantitatively is added for preparation. In the natural process, the process of oil pollution of soil may be long, and the mechanism of action is very complex. In order to ensure that the diesel oil and soil samples have sufficient physical and chemical reaction, the prepared contaminated soil samples are sealed and preserved for one week before the relevant property test.

\section{Laboratory test of diesel contaminated soil}

\subsection{Grain distribution analysis test}

Because the soil sample is low liquid limit clay after pretreatment, the particle size analysis of diesel contaminated soil sample adopts densimeter method. According to the requirements of the standard for soil test methods (GB / T 50123-2019) ${ }^{[5]}$, the particle analysis test is carried out. There are two cases of the sample with and without dispersant. The test results are shown in Table 2.

Comparing the test results with dispersant or not, it is found that the content of medium sand and fine sand $(0.25-0.75 \mathrm{~mm}, 0.075-0.25 \mathrm{~mm})$ has no change, while the content of silt group (0.005-0.075mm) decreases significantly after adding dispersant, which results in the increase of clay group $(<0.005 \mathrm{~mm})$, which is due to the existence of some compounds in the soil, makes the clay with small particle size cemented into silt particles, but under the action of dispersant, these fake silt particles are dispersed again, which shows that the soil sample has a certain degree of fake powder. The next step of particle analysis with different oil content is carried out with the data of adding dispersant.

Table 2. Particle size composition analysis of soil sample

\begin{tabular}{|c|c|c|c|c|c|}
\hline $\begin{array}{c}\text { Oil } \\
\text { Ontent } \\
(\%)\end{array}$ & Dispersant & $\begin{array}{c}\text { Medium } \\
\text { sand }(\mathrm{mm})\end{array}$ & $\begin{array}{c}\text { Fine } \\
\text { sand } \\
(\mathrm{mm})\end{array}$ & $\begin{array}{c}\text { Silt } \\
(\mathrm{mm})\end{array}$ & $\begin{array}{c}\text { Clay } \\
(\mathrm{mm})\end{array}$ \\
\cline { 2 - 6 } & & $0.5 \sim 0.25$ & $\begin{array}{c}0.25 \sim \\
0.075\end{array}$ & $\begin{array}{c}0.075 \sim \\
0.005\end{array}$ & $<0.005$ \\
\hline \multirow{2}{*}{0} & No & 0.22 & 1.63 & 87.27 & 10.88 \\
\cline { 2 - 6 } & Yes & 0.22 & 1.63 & 72.74 & 25.41 \\
\hline \multirow{2}{*}{4} & No & 0.2 & 0.9 & 93.94 & 4.96 \\
\cline { 2 - 6 } & Yes & 0.2 & 0.9 & 73.49 & 25.41 \\
\hline \multirow{2}{*}{8} & No & 0.11 & 0.9 & 95.75 & 3.24 \\
\cline { 2 - 6 } & Yes & 0.11 & 0.9 & 56.58 & 42.41 \\
\hline \multirow{2}{*}{12} & No & 0.23 & 0.79 & 82.80 & 16.18 \\
\cline { 2 - 6 } & Yes & 0.23 & 0.79 & 59.43 & 39.55 \\
\hline \multirow{2}{*}{16} & No & 0.09 & 0.81 & 93.84 & 5.26 \\
\cline { 2 - 6 } & Yes & 0.09 & 0.81 & 63.02 & 36.08 \\
\hline
\end{tabular}

According to the results of particle test, with the increase of oil content, the content of clay group first increased significantly, reached the peak value when the oil content was $8 \%$, and then decreased slightly. This is because there are colloids in soil particles, such as organic or inorganic colloidal compounds, free oxide colloids or soluble salts, which may dissolve due to the addition of diesel oil, resulting in the weakening of the connection between particles ${ }^{[6]}$, the larger particles are decomposed into smaller particles, resulting in the increase of clay content. When the oil content is more than $8 \%$, the viscosity of diesel oil will make the particles bond to a certain extent, and the viscosity will be slightly reduced. But on the whole, the clay content of the diesel contaminated soil is higher than that of the unpolluted soil.

\subsection{Specific gravity test}

The specific gravity of soil samples with different oil content is tested by the indoor Pycnometer method, and the results are shown in Figure 1. It can be seen from the figure that, with the increase of oil content, the specific gravity value decreases continuously, indicating that the diesel content in the soil has a greater impact on the specific gravity value of soil particles.

The mineral in the soil is a decisive factor for the specific gravity of soil particles. The presence of organic and inorganic colloidal compounds, free oxide colloids or soluble salts may dissolve due to the addition of diesel [6], resulting in the decrease of mineral composition of soil particles, so the specific gravity value decreases with the increase of oil content. 


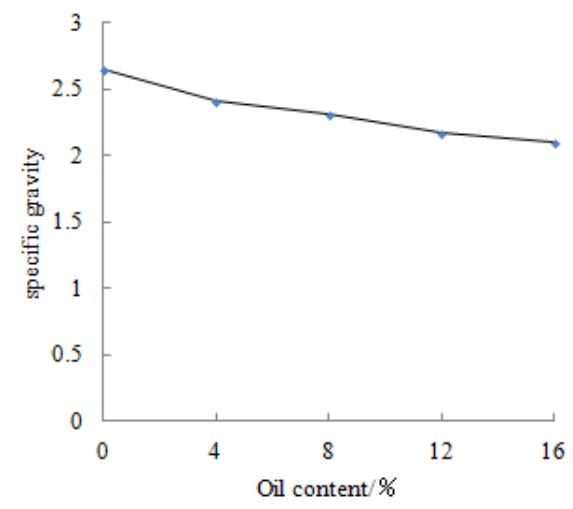

Fig. 2. Relation curve between specific gravity and oil content

\subsection{Limit water content test}

In engineering practice, plastic limit $\omega_{\mathrm{P}}$ and liquid limit $\omega_{\mathrm{L}}$ are two important limiting water contents that determine the engineering properties of soil ${ }^{[7]}$. Different liquid-plastic limit values reflect the difference of particle size composition and mineral composition of soil ${ }^{[8]}$. In this paper, the soil samples with different oil content are tested. The results show that the liquidplastic limit of the soil samples has changed due to the addition of diesel oil, as shown in Figure 2.

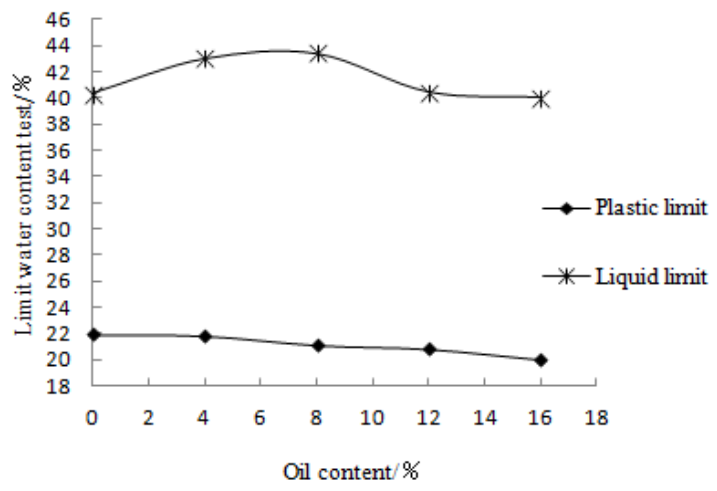

Fig.3. Relation curve between liquid plastic limit and oil content

As can be seen from Figure 2, when the oil content increases, the liquid limit increases, when the oil content reaches $8 \%$, the liquid limit reaches the peak value, and then the liquid limit begins to decrease. However, the plastic limit decreases with the increase of oil content. The decrease of plastic limit can be explained by the theory of diffusion double electric layer ${ }^{[9]}$. Diesel and water are two immiscible liquids, and water molecules are polar. Diesel molecules are basically nonpolar, which can not form polar covalent bond with clay particles like water ${ }^{[10]}$. The soil particles are wrapped by oil, and the hydrophobicity of oil results in the decrease of water content acting on the particles. At this time, the thickness of the double electric layer becomes thinner, and the plastic limit of the soil decreases. The change of liquid limit can be explained by the viscosity characteristics of pollutants ${ }^{[11]}$. The thin layer formed by diesel oil and the adjacent soil particles act as a cohesive interface to keep the clay structure independent under its own gravity.
Due to the viscosity of diesel oil, it is necessary to add some water on the basis of the original water content to offset the adhesion between particles caused by diesel oil, so the liquid limit is increased. For heavily polluted soil samples (when the diesel content is more than $8 \%$ ), the lubrication between soil particles begins to slide when the thickness of the viscous interface exceeds the critical value, thus reducing the liquid limit.

\section{Conclusion}

Through the above research and analysis, the results show that the addition of diesel oil will change the basic properties of soil samples, thus affecting the engineering properties of soil samples. The corresponding conclusions are as follows:

(1) The addition of diesel oil has a greater impact on the silt and clay particles in the soil. The connection between the particles is weakened due to diesel oil, and the silt particles are decomposed into smaller particles. The content of clay particles is significantly higher than that of unpolluted soil samples.

(2) With the increase of diesel oil content, the specific gravity of soil sample decreases gradually, and it is smaller than the uncontaminated soil.

(3) With the increase of oil content, the plastic limit of soil sample decreases, the liquid limit increases first, reaches a peak value when oil content is $8 \%$, and then decreases.

\section{Acknowledgments}

This research was financially supported by the Science and Technology Department of Jilin Province (No. 20170204030SF) and the Education Department of Jilin Province (No. JJKH20190856KJ).

\section{References}

1. Habib-ur-Rahman, S.N. Abdujauwad and T. Akram. Geotechnical behavior of oil-contaminated fine grained soils. Electron. J.Geotech.Eng. 12(2007)

2. Mackenzie, J.M.W. Interaction between oil drops and mineral surfaces. Soc. Min. Eng., AIME., Trans,247(1970)

3. LIU Han-long, ZHU Chun-peng, et al. Fundamental physical properties of soil polluted by acid and alkali in laboratory $[\mathrm{J}]$. Chinese Journal of Geotechnical Engineering,30 (2008)

4. TONG Ling. Study on water-physical and mechanical properties of oil-contaminated soils [D]. Qingdao: Ocean University of China, (2008)

5. GB/T50123 - 2019 Standard for soil test method[S]. (2019)

6. MITCHELL J K, SOGA Kenichi. Fundamentals of soil behavior [M]. 3rd ed. New Jersey: John Wiley \& Son, (2005) 
7. TANG Da-xiong, LIU You-rong, et al. Rock and soils engineering $[\mathrm{M}]$. 2nd ed. Beijing: Geological Publishing House, (1999)

8. COTECCHIA F, CHANDLER $\mathrm{R} \mathrm{J}$, A general framework for the mechanical behavior of clays[J]. Geotechnique, 48 (2000)

9. Winterkorn, H.F., Pamukcu, S. Soil stabilization and grouting, in: Fang, H.-Y. (Ed), Foundation engineering handbook. Van Nostrand Reinhold, New York, NY, (1990)

10. ELAHE $\mathrm{K}$, HASAN $\mathrm{G}$, MOHAMMAD $\mathrm{R} \mathrm{S}$, HESSAM Y.Geotechnical properties of gas oilcontaminated Kaolinite [J]. Engineering Geology, 166 (2013)

11. Jia, Y.G., Wu, Q., Shang, H., Yang, Z.N., Shan, H.X. The influence of oil contamination on the geotechnical properties of costal sediments in the Yellow River Delta, China[J]. Bulletin of Engineering Geology and the Environment, 70 (2011) 